\title{
Faktor-faktor yang Mempengaruhi Terhadap Pengetahuan Tentang Lingkungan pada Siswa Tingkat SMP/MTS N dan SMA/MAN Adiwiyata di Kota Labuhanbatu
}

\author{
Endang Silalahi, Syarifuddin, Mufti Sudibyo \\ Program Studi Pendidikan Biologi. Program Pascasarjana \\ Universitas Negeri Medan, Sumatera Utara, Indonesia
}

\begin{abstract}
Abstrak: Penelitian bertujuan untuk mengetahui faktor-faktor yang mempengaruhi terhadap: pengetahuan siswa tentang lingkungan pada siswa tingkat SMP/MTs N dan SMA/MAN Adiwiyata di Kota Labuhanbatu. Metode penelitian menggunakan deskriptif kualitatif dan kuantitatif dengan sampel penelitian sebanyak 240 siswa dari kelas XI SMA/MAN dan VIII SMP/MTs N yang ditentukan menggunakan teknik random sampling. Instrumen yang digunakan adalah tes pengetahuan siswa tentang lingkungan dalam bentuk pilihan ganda yang berjumlah 30 soal. Teknik analisis data menggunakan uji t, dan Anava pada taraf signifikan $\alpha=0,05$ dan dilanjutkan menggunakan uji tukey dengan bantuan program SPSS 21.0 for Windows. Hasil penelitian ini diperoleh bahwa: (1) terdapat perbedaan pengetahuan tentang lingkungan antara siswa SMP/MTs N dan SMA/MAN Adiwiyata di Kabupaten Labuhanbatu $\left(\mathrm{t}_{\text {hitung }}=4,109 ; \mathrm{P}=0,000\right) ;(2)$ terdapat pengaruh tingkat pendidikan orangtua terhadap pengetahuan lingkungan (Fhitung $=3,410 ; \mathrm{P} .=0,003$ ); (3) terdapat pengaruh pekerjaan orang tua terhadap pengetahuan lingkungan (Fhitung $=3,010 ; \mathrm{P} .=0,000) ;(4)$ tidak terdapat pengaruh jenis kelamin siswa terhadap pengetahuan lingkungan (Fhitung $=0,373 ; \mathrm{P} .=0,542$ ); dan (5) terdapat pengaruh sumber informasi terhadap pengetahuan lingkungan pada siswa SMP/MTs $\mathrm{N}$ dan SMA/MAN Adiwiyata di Kabupaten Labuhanbatu (Fhitung = 6,593; P. = 0,000). Hasil penelitian ini mengimplikasikan bahwa faktor-faktor yang mempengaruhi terhadap pengetahuan siswa tentang lingkungan memiliki peranan penting terhadap sikap kepedulian siswa kepada lingkungan.
\end{abstract}

Kata Kunci: Pengetahuan, Lingkungan Hidup

\section{PENDAHULUAN}

Permasalahan lingkungan hidup tidak dapat dipecahkan secara teknis semata, namun yang lebih penting adalah pemecahan yang dapat mengubah mental serta kesadaraan akan pengelolaan lingkungan. Berkaitan dengan perilaku manusia terhadap kondisi sumber daya alam dan lingkungan yang cenderung tidak perduli, maka mengubah perilaku menjadi perioritas utama dalam mengatasi krisis lingkungan. Salah satu cara dalam upaya mengubah perilaku adalah melalui jalur pendidikan (Aprilia, 2015). Pendidikan lingkungan hidup melalui Program Adiwiyata mendorong terciptanya pengetahuan dan kesadaran warga sekolah agar memiliki wawasan konservasi dalam upaya pelesatarian lingkungan hidup. Program ini diharapkan setiap warga sekolah ikutterlibat dalam kegiatan sekolah menuju lingkungan yang sehat serta menghindari dampak lingkungan yang negatif (Kementerian Negara Lingkungan Hidup, 2012). Pendidikan lingkungan hidup disekolah merupakan salah satu dari penerapan pendidikan karakter.

Pendidikan karakter dan pendidikan lingkungan hidup menanamkan nilai-nilai karakter kepada warga sekolah yang meliputi pengetahuan (kognitif), kesadaran atau kemauan (afektif) dan tindakan (psikomotor) untuk melaksanakan nilainilai tersebut. Pengetahuan, nilai sikap, dan wawasan mengenai lingkungan hidup perlu diberikan sejak dini kepada lapisan masyarakat dan peserta didik dari seluruh jenjang pendidikan melalui pendidikan lingkungan. Pendidikan lingkungan adalah upaya mengubah perilaku dan sikap yang dilakukan oleh masyarakat yang bertujuan untuk meningkatkan pengetahuan, keterampilan, dan kesadaran masyarakat tentang nilai-nilai dan isu lingkungan untuk kepentingan generasi sekarang dan generasi yang akan datang (Hasyim, 2010). Melalui pendidikan lingkungan diharapkan dapat meningkatkan kepedulian peserta didik terhadap lingkungan dan menanamkan nilai-nilai konservasi lingkungan sejak dini 
(Sharma dan Tan, 1990). Sekolah yang telah mendapatkan predikat Adiwiyata dianggap telah berhasil membentuk karakter peduli terhadap lingkungan dan keadaan orangtua siswa juga sangat mempengaruhi terhadap pengetahuan dan terlebih sikap peduli lingkungan hidup siswa. Hal ini diketahui dari beberapa penelitian terdahulu, diantaranya yang dilakukan oleh Saragih (2012), yang mengemukakan bahwa ada pengaruh yang positif dari program Adiwiyata terhadap kognitif, afektif, dan psikomotorik lingkungan siswa. Sedangkan menurut Yupiter L. Manurung (2011) yang memaparkan hasil penelitian menunjukkan bahwa program Adiwiyata yang diimplementasikan di SDN Panggang 04 Jepara telah menumbuh kembangkan karakter peduli lingkungan dari warga sekolah tersebut, yang dapat dilihat melalui kegiatan seperti menanam dan merawat tanaman, memilah dan membuang sampah, menghemat pemakaian air, listrik, dan kertas, dan lain-lain.

Berdasarkan penelitian oleh Mulyana (2009) dengan judul Penanaman Etika Lingkungan Melalui Sekolah Peduli dan Berbudaya Lingkungan, yang diterbitkan melalui Jurnal Tabularasa PPs Unimed Vol. 6 No. 2 Desember 2009, mengatakan bahwa pendidikan lingkungan hidup yang dilakukan di sekolah peduli dan berbudaya lingkungan dinilai efektif dalam menanamkan kepedulian terhadap kelestarian sumber daya alam dan lingkungan.Berdasarkan penelitianpenelitian diatas menegaskan bahwa keefektifan sekolah berpredikat Adiwiyata dalam membentuk karakter peduli lingkungan hidup siswa.

\section{METODE PENELITIAN}

Penelitian ini dilaksanakan di seluruh siswa kelas XI yang mengikuti program Adiwiyata di MAN 1 Rantauprapat, SMA Negeri 1 Rantau Selatan dan siswa kelas VIII MTS Negeri 1 Rantauprapat, SMP Negeri 3 Rantau Utara yang berjumlah keseluruhan 26 kelas. Waktu penelitian ini dilaksanakan pada bulan Maret s/d Mei 2016. Pengambilan sampel dalam penelitian ini dilakukan dengan menggunakan teknik Random Sampling dimana sampel dalam penelitian ini dalah siswa SMA/MAN kelas XI masing-masing SMA sebanyak 30 orang sehingga jumlah seluruh siswa SMA/MAN 120 orang dan siswa SMP/MTS N 120 orang. Total keseluruhan sampel sebanyak 240 orang. Variabel bebas dalam penelitan ini adalah pendidikan orang tua $\left(\mathrm{X}_{1}\right)$, pekerjaan orang tua $\left(\mathrm{X}_{2}\right)$, Jenis kelamin siswa $\left(\mathrm{X}_{3}\right)$, dan sumber informasi $\left(\mathrm{X}_{4}\right)$. Variabel terikat dalam penelitian ini adalah pengetahuan lingkungan (Y)

\section{Teknik Pengumpulan dan Analisis Data}

Instrumen yang digunakan adalah tes pengetahuan siswa tentang lingkungan dalam bentuk pilihan ganda yang berjumlah 30 soal, setiap jawaban yang benar diberi skor 1, sedangkan jawaban yang salah diberi skor 0. Nilai tersebut dikonversikan kepada nilai dengan rentang 0-100. Teknik analisis data menggunakan uji t, dan Anava pada taraf signifikan $\alpha=0,05$ dan dilanjutkan menggunakan uji tukey dengan bantuan program SPSS 21.0 for Windows.

\section{HASIL PENELITIAN \\ Deskripsi Nilai Pengetahuan tentang Lingkungan pada Siswa SMP/MTs N dan SMA/MAN Adiwiyata di Kabupaten Labuhanbatu}

Tabel 1. Deskripsi Pengetahuan tentang Lingkungan antara Siswa SMP/MTs N dan SMA/MAN Adiwiyata di Kabupaten Labuhanbatu

\begin{tabular}{clcc}
\hline No. & \multicolumn{1}{c}{ Sekolah } & Rata-rata Nilai & Standard Deviasi \\
\hline 1. & MAN 1 Rantauprapat & 69,33 & 13,62 \\
2. & SMA Negeri 1 Rantau Selatan & 68,28 & 10,71 \\
\hline & Rata-rata & $\mathbf{6 8 , 8 0}$ & $\mathbf{1 2 , 2 1}$ \\
\hline 3. & MTS Negeri 1 Rantauprapat & 65,44 & 10,87 \\
4. & SMP Negeri 3 Rantau Utara & 60,00 & 12,71 \\
\hline & Rata-rata & $\mathbf{6 2 , 7 2}$ & $\mathbf{1 2 , 0 9}$ \\
\hline & Total Rata-rata & $\mathbf{6 5 , 7 6}$ & $\mathbf{1 2 , 5 0}$ \\
\hline
\end{tabular}




\section{Deskripsi Nilai Pengetahuan Lingkungan Siswa}

Tabel 2. Deskripsi Nilai Pengetahuan Lingkungan Siswa (MAN 1 Rantauprapat, SMA Negeri 1 Rantau Selatan, MTs Negeri 1 Rantauprapat, SMP Negeri 3 Rantau Utara) Dilihat Berdasarkan Tingkat Pendidikan Orangtua

\begin{tabular}{ccccc}
\hline No. & $\begin{array}{c}\text { Tingkat Pendidikan } \\
\text { Orangtua }\end{array}$ & Jumlah & $\begin{array}{c}\text { Rata-rata Nilai Pengetahuan } \\
\text { Lingkungan }\end{array}$ & $\begin{array}{c}\text { Standard } \\
\text { Deviasi }\end{array}$ \\
\hline 1. & D1 & 1 & 66,67 & $\cdot$ \\
2. & D3 & 5 & 64,66 & 10,95 \\
3. & S1 & 52 & 69,87 & 8,37 \\
4. & S2 & 15 & 73,99 & 10,01 \\
5. & SD & 16 & 60,20 & 12,07 \\
6. & SMA & 122 & 63,55 & 13,95 \\
7. & SMP & 29 & 66,66 & 10,57 \\
\hline & Rata-rata & $\mathbf{2 4 0}$ & $\mathbf{6 5 , 7 6}$ & $\mathbf{1 2 , 5 0}$ \\
\hline
\end{tabular}

\section{Deskripsi Nilai Pengetahuan Lingkungan Siswa}

Tabel 3. Deskripsi Nilai Pengetahuan Lingkungan Siswa (MAN 1 Rantauprapat, SMA Negeri 1 Rantau Selatan, MTs Negeri 1 Rantauprapat, SMP Negeri 3 Rantau Utara) Dilihat Berdasarkan Jenis Pekerjaan Orangtua

\begin{tabular}{|c|c|c|c|c|}
\hline No. & $\begin{array}{c}\text { Jenis Pekerjaan } \\
\text { Orangtua } \\
\end{array}$ & Jumlah & $\begin{array}{c}\text { Rata-rata Nilai Pengetahuan } \\
\text { Lingkungan }\end{array}$ & $\begin{array}{l}\text { Standard } \\
\text { Deviasi }\end{array}$ \\
\hline 1. & BUMN & 9 & 71,11 & 6,45 \\
\hline 2. & Buruh Bangunan & 1 & 70,00 & 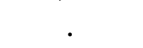 \\
\hline 3. & Dokter & 4 & 78,33 & 5,77 \\
\hline 4. & Dosen & 1 & 70,00 & . \\
\hline 5. & Guru & 6 & 67,22 & 12,72 \\
\hline 6. & Mekanik & 1 & 73,33 & . \\
\hline 7. & Nelayan & 1 & 66,67 & • \\
\hline 8. & Pedagang & 1 & 70,00 & . \\
\hline 9. & Penjahit & 5 & 59,99 & 23,92 \\
\hline 10. & Petani & 44 & 69,16 & 13,64 \\
\hline 11. & PNS & 54 & 70,86 & 7,58 \\
\hline 12. & POLRI & 6 & 69,99 & 4,21 \\
\hline 13. & Supir & 1 & 63,33 & $\cdot$ \\
\hline 14. & TNI & 2 & 75,00 & 7,07 \\
\hline 15. & Tukang Bangunan & 10 & 54,99 & 10,80 \\
\hline 16. & Tukang Becak & 10 & 60,66 & 15,77 \\
\hline 17. & Tukang Bengkel & 1 & 43,33 & . \\
\hline 18. & Tukang Pangkas & 1 & 36,67 & . \\
\hline 19. & Wiraswasta & 77 & 61,29 & 11,78 \\
\hline 20. & Wirausaha & 5 & 63,33 & 16,49 \\
\hline & Rata-rata & 240 & 65,76 & 12,50 \\
\hline
\end{tabular}

\section{Deskripsi Nilai Pengetahuan Lingkungan Siswa}

Tabel 4. Deskripsi Nilai Pengetahuan Lingkungan Siswa (MAN 1 Rantauprapat, SMA Negeri 1 Rantau Selatan, MTs Negeri 1 Rantauprapat, SMP Negeri 3 Rantau Utara) Dilihat Berdasarkan Jenis Kelamin Siswa

\begin{tabular}{|c|c|c|c|c|}
\hline No. & $\begin{array}{c}\text { Jenis Kelamin } \\
\text { Siswa }\end{array}$ & Jumlah & $\begin{array}{c}\text { Rata-rata Nilai Pengetahuan } \\
\text { Lingkungan }\end{array}$ & $\begin{array}{l}\text { Standard } \\
\text { Deviasi }\end{array}$ \\
\hline 1. & Laki-laki & 98 & 65,16 & 12,06 \\
\hline 2. & Perempuan & 142 & 66,17 & 12,82 \\
\hline & Rata-rata & 240 & 65,76 & 12,50 \\
\hline
\end{tabular}




\section{Deskripsi Nilai Pengetahuan Lingkungan pada Siswa}

Tabel 5. Deskripsi Nilai Pengetahuan Lingkungan pada Siswa (MAN 1 Rantauprapat, SMA Negeri 1 Rantau Selatan, MTs Negeri 1 Rantauprapat, SMP Negeri 3 Rantau Utara) Dilihat Berdasarkan Sumber Informasi Siswa

\begin{tabular}{ccccc}
\hline No. & $\begin{array}{c}\text { Sumber Informasi } \\
\text { Siswa }\end{array}$ & Jumlah & $\begin{array}{c}\text { Rata-rata Nilai Pengetahuan } \\
\text { Lingkungan }\end{array}$ & $\begin{array}{c}\text { Standard } \\
\text { Deviasi }\end{array}$ \\
\hline 1. & Guru & 75 & 66,84 & 11,38 \\
2. & Internet & 33 & 61,91 & 12,38 \\
3. & Media TV & 56 & 61,24 & 12,97 \\
4. & Orang Tua & 76 & 69,69 & 11,95 \\
\hline & Rata-rata & $\mathbf{2 4 0}$ & $\mathbf{6 5 , 7 6}$ & $\mathbf{1 2 , 5 0}$ \\
\hline
\end{tabular}

\section{Pengujian Hipotesis}

Perbedaan Pengetahuan tentang Lingkungan antara Siswa SMP/MTs N dan SMA/MAN Adiwiyata Di Kabupaten Labuhanbatu

Berdasarkan hasil uji hipotesis diperoleh bahwa terdapat perbedaan pengetahuan tentang lingkungan antara siswa SMP/MTs $\mathrm{N}$ dan SMA/MAN Adiwiyata di Kabupaten Labuhanbatu $\left(\mathrm{t}_{\text {hitung }}=4,109 ; \mathrm{P}=0,000\right)$. Hal ini dapat dilihat bahwa rata-rata nilai pengetahuan lingkungan pada siswa MAN 1 Rantauprapat, SMA Negeri 1 Rantau Selatan $68,80 \pm 12,21(\bar{X} \pm \mathrm{SD})$ signifikan lebih tinggi daripada rata-rata nilai pengetahuan lingkungan pada siswa MTs Negeri 1 Rantauprapat, SMP Negeri 3 Rantau Utara 62,72 $\pm 12,09$.

Pengaruh Tingkat Pendidikan Orangtua terhadap Pengetahuan Lingkungan pada Siswa SMP/MTs N dan SMA/MAN Adiwiyata Di Kabupaten Labuhanbatu

Berdasarkan hasil uji hipotesis diperoleh bahwa terdapat pengaruh tingkat pendidikan orangtua terhadap pengetahuan lingkungan pada siswa SMP/MTs $\mathrm{N}$ dan SMA/MAN Adiwiyata di Kabupaten Labuhanbatu (Fhitung = 3,410; P. = 0,003). Terdapat pengaruh tingkat pendidikan orangtua terhadap pengetahuan lingkungan pada siswa MAN 1 Rantauprapat, SMA Negeri 1 Rantau Selatan di Kabupaten Labuhanbatu (Fhitung = 2,517; P. = 0,025). Terdapat pengaruh tingkat pendidikan orangtua terhadap pengetahuan lingkungan pada siswa MTs Negeri 1 Rantauprapat,
SMP Negeri 3 Rantau Utara di Kabupaten Labuhanbatu (Fhitung = 4,289; P. = 0,001).

Pengaruh Pekerjaan Orang Tua terhadap Pengetahuan Lingkungan pada Siswa SMP/MTS N dan SMA/MAN Adiwiyata Di Kabupaten Labuhanbatu

Berdasarkan hasil uji hipotesis diperoleh bahwa terdapat pengaruh pekerjaan orang tua terhadap pengetahuan lingkungan pada siswa SMP/MTs $\mathrm{N}$ dan SMA/MAN Adiwiyata di Kabupaten Labuhanbatu (Fhitung $=3,010 ;$ P. $=0,000$ ). Tidak terdapat pengaruh pekerjaan orang tua terhadap pengetahuan lingkungan pada siswa MAN 1 Rantauprapat, SMA Negeri 1 Rantau Selatan di Kabupaten Labuhanbatu (Fhitung $=1,045 ;$ P. $=0,417)$. Terdapat pengaruh pekerjaan orang tua terhadap pengetahuan lingkungan pada siswa MTs Negeri 1 Rantauprapat, SMP Negeri 3 Rantau Utara di Kabupaten Labuhanbatu (Fhitung = 4,736; P. = 0,000).

Pengaruh Jenis Kelamin Siswa terhadap Pengetahuan Lingkungan pada Siswa SMP/MTs N dan SMA/MAN Adiwiyata Di Kabupaten Labuhanbatu

Berdasarkan hasil uji hipotesis diperoleh bahwa tidak terdapat pengaruh jenis kelamin siswa terhadap pengetahuan lingkungan pada siswa SMP/MTs $\mathrm{N}$ dan SMA/MAN Adiwiyata di Kabupaten Labuhanbatu (Fhitung $=0,373 ; \mathrm{P} .=0,542$ ). Tidak terdapat pengaruh jenis kelamin siswa terhadap pengetahuan lingkungan pada siswa MAN 1 Rantauprapat, SMA Negeri 1 Rantau Selatan di Kabupaten Labuhanbatu (Fhitung $=2,615 ;$ P. $=0,109$ ). 
Tidak terdapat pengaruh jenis kelamin siswa terhadap pengetahuan lingkungan pada siswa MTs Negeri 1 Rantauprapat, SMP Negeri 3 Rantau Utara di Kabupaten Labuhanbatu (Fhitung $=0,141 ;$ P. $=0,708$ ).

Pengaruh Sumber Informasi terhadap Pengetahuan Lingkungan pada Siswa SMP/MTs N dan SMA/MAN Adiwiyata Di Kabupaten Labuhanbatu

Berdasarkan hasil uji hipotesis diperoleh bahwa terdapat pengaruh sumber informasi terhadap pengetahuan lingkungan pada siswa SMP/MTs N dan SMA/MAN Adiwiyata di Kabupaten Labuhanbatu (Fhitung $=6,593 ; \mathrm{P} .=0,000)$. Terdapat pengaruh sumber informasi terhadap pengetahuan lingkungan pada siswa MAN 1 Rantauprapat, SMA Negeri 1 Rantau Selatan di Kabupaten Labuhanbatu (Fhitung $=4,272 ; \mathrm{P} .=0,007)$. Terdapat pengaruh sumber informasi terhadap pengetahuan lingkungan pada siswa MTs Negeri 1 Rantauprapat, SMP Negeri 3 Rantau Utara di Kabupaten Labuhanbatu (Fhitung = 8,836; P. = 0,001).
Uji Lanjut (Posthoc) Tukey Perbedaan Nilai Pengetahuan tentang Lingkungan antara Siswa SMP/MTs $\mathbf{N}$ dan SMA/MAN Adiwiyata Di Kabupaten Labuhanbatu

Hasil penelitian ini menunjukkan bahwa nilai pengetahuan lingkungan pada siswa MAN 1 Rantauprapat mempunyai nilai rata-rata tertinggi sebesar $69,33 \pm$ 13,62 ( $\bar{X} \pm$ SD), namun tidak berbeda signifikan dengan nilai pengetahuan lingkungan pada siswa: (1) SMA Negeri 1 Rantau Selatan 68,27 \pm 10,71; dan (2) MTs Negeri 1 Rantauprapat $65,44 \pm 10,87$. Nilai pengetahuan lingkungan pada siswa SMP Negeri 3 Rantau Utara 59,99 \pm 12,71 tidak berbeda signifikan dengan nilai pengetahuan lingkungan pada siswa MTs Negeri 1 Rantauprapat, namun berbeda signifikan dengan nilai pengetahuan lingkungan pada siswa: (1) SMA Negeri 1 Rantau Selatan; dan (2) MAN 1 Rantauprapat. Nilai pengetahuan lingkungan pada siswa SMP Negeri 3 Rantau Utara mempunyai nilai terendah dibanding dengan nilai pengetahuan lingkungan pada siswa lainnya.

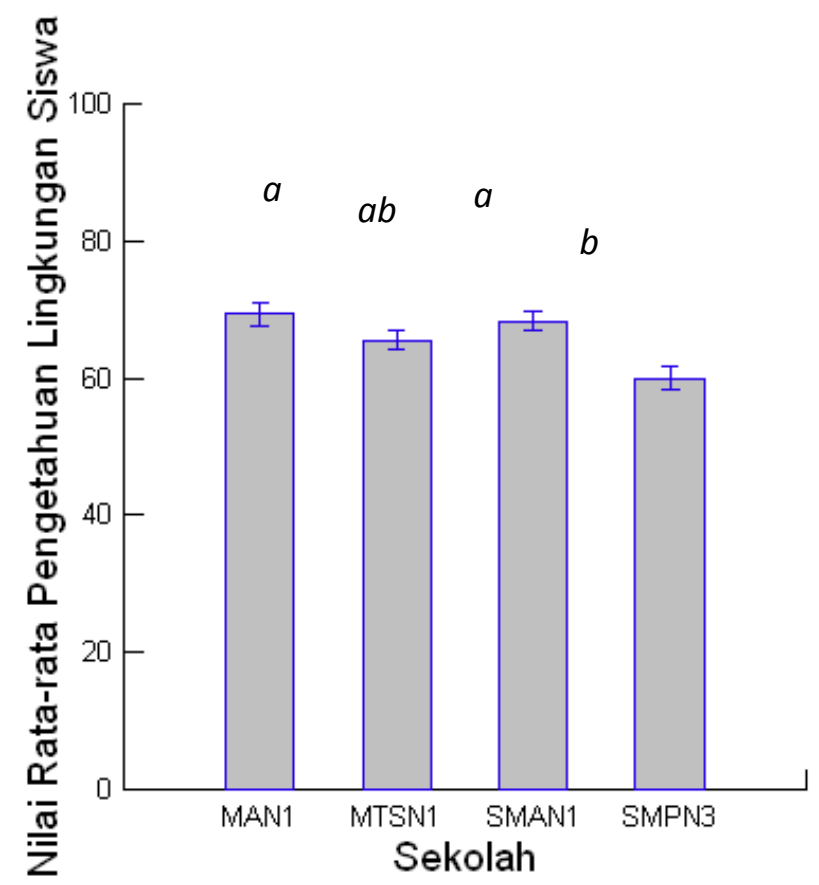

Gambar 4.1. Perbedaan Pengetahuan tentang Lingkungan antara Siswa SMP/MTs N dan SMA/MAN Adiwiyata di Kabupaten Labuhanbatu ( $\left.\mathrm{t}_{\text {hitung }}=4,109 ; \mathrm{P}=0,000\right)$ 
PEMBAHASAN

\section{Perbedaan Pengetahuan tentang Lingkungan antara Siswa SMP/MTs N dan SMA/MAN Adiwiyata Di Kabupaten Labuhanbatu}

Pada hasil penelitian ini diperoleh bahwa terdapat perbedaan pengetahuan tentang lingkungan antara siswa SMP/MTs $\mathrm{N}$ dan SMA/MAN Adiwiyata di Kabupaten Labuhanbatu. Hal ini dikarenakan bahwa rata-rata nilai pengetahuan lingkungan pada siswa MAN 1 Rantauprapat, SMA Negeri 1 Rantau Selatan signifikan lebih tinggi daripada rata-rata nilai pengetahuan lingkungan pada siswa MTs Negeri 1 Rantauprapat, SMP Negeri 3 Rantau Utara. Sebagaimana diketahui bahwa ilmu pengetahuan terutama sains adalah ciptaan pikiran manusia dengan semua gagasan dan konsepnya yang ditemukan secara bebas, namun untuk mendapatkan konsep dan teori ini tidak menuruti pengamatan induktif yang sederhana seperti suasana dan kondisi sekolah sangat perlu diperhatikan, karena lingkungan yang bersih dan nyaman dapat meningkatkan suasana belajar yang harmonis dan dapat meningkatkan kondisi belajar dengan penuh keakraban. Pengetahuan merupakan kumpulan fakta, dan pengetahuan lebih dianggap sebagai suatu proses pembentukan yang terusmenerus, terus berkembang dan berubahubah. Von Glasefeld (1996) menekankan bahwa pengetahuan bukanlah suatu tiruan dari kenyataan (realitas). Pengetahuan bukanlah gambaran dari dunia kenyataan yang ada, tetapi pengetahuan selalu merupakan akibat dari suatu konstruksi kognitif kenyataan melalui kegiatan seseorang.

Battencourt (1989) mengemukakan bahwa Seseorang membentuk skema, kategori, konsep dan struktur pengetahuan yang diperlukan untuk pengetahuan. Maka itu, pengetahuan bukanlah tentang dunia lepas dari pengamatan tetapi merupakan ciptaan manusia yang dikonstruksikan dari pengalaman atau dunia sejauh dialaminya. Menurut Piaget (1971) bahwa proses kontruksi ini berjalan terus menerus dengan setiap kali mengadakan reorganisasi karena adanya suatu pemahaman yang baru.
Pengetahuan tidak dapat dipindahkan begitu saja dari otak seorang guru, misalkan kepada seorang murid. Murid sendirilah yang harus mengartikan apa yang telah diajarkan dengan menyesuaikan terhadap pengalaman-pengalaman mereka (Lorsbach dan Tobin 1992). Pengetahuan lebih menunjukkan pada pengalaman seseorang akan dunia dari pada dunia itu sendiri. Tanpa pengalaman itu seseorang tidak dapat membentuk pengetahuan. Pengalaman tidak harus diartikan sebagai pengalaman fisik saja, tetapi juga dapat diartikan sebagai pengalaman kognitif dan mental. Menurut von Glasersfeld (1996), bahwa pengetahuan itu pula dibentuk oleh struktur konsepsi seseorang sewaktu dia berinteraksi dengan lingkungannya.

\section{Pengaruh Tingkat Pendidikan Orangtua} terhadap Pengetahuan Lingkungan pada Siswa SMP/MTs $N$ dan SMA/MAN Adiwiyata Di Kabupaten Labuhanbatu

Pada hasil penelitian ini diperoleh bahwa terdapat pengaruh tingkat pendidikan orangtua terhadap pengetahuan lingkungan pada siswa SMP/MTs $\mathrm{N}$ dan SMA/MAN Adiwiyata di Kabupaten Labuhanbatu. Hal ini dikarenakan bahwa tingkat pendidikan orang tua siswa memiliki peranan penting kepada siswa sebagaimana peran orang tua dalam memberikan nasehat dan pengetahuan kepada para siswa untuk selalu menjaga lingkungan dan melestarikannya dalam proses pembelajaran siswa mengenai lingkungan. Peran orang tua terhadap anaknya sangat dapat mengarahkan anaknya ke arah yang paling baik untuk dapat hidup lebih baik. Dalam hal menjaga lingkungan agar tetap terjaga dan meningkatkan kesehatan bagi lingkungan sekitar. Orang tua selalu berusaha memberikan dunia pendidikan yang positif bagi buah hatinya agar berguna bagi orang banyak. Perhatian dan didikan orang tua dapat meningkatkan pengetahuan lingkungan bagi anaknya.

Pengaruh Pekerjaan Orang Tua terhadap Pengetahuan Lingkungan pada 


\section{Siswa SMP/MTS $\mathbf{N}$ dan SMA/MAN Adiwiyata Di Kabupaten Labuhanbatu}

Pada hasil penelitian ini diperoleh bahwa terdapat pengaruh pekerjaan orang tua terhadap pengetahuan lingkungan pada siswa SMP/MTs $\mathrm{N}$ dan SMA/MAN Adiwiyata di Kabupaten Labuhanbatu. Hal ini dikarenakan pekerjaan orang tua memiliki peranan penting terhadap pengetahuan orang tua. Hal ini dapat dilihat berdasarkan dari pengalaman orang tua siswa mengenai pengetahuan lingkungan yang telah dipelajarinya melalui profesi kerja yang dimiliki oleh orang tua masingmasing siswa yang diberikan bentuk pengajarannya kepada para siswa dari pengalaman belajar orang tua. Arahan yang diberikan orang tua berupa nasihat yang baik masih dapat dilakukan dan dikerjaan anaknya sehingga belajar mengenai lingkungan menjadi termotivasi untuk dapat meningkatakan pengetahuan lingkungan.

\section{Pengaruh Jenis Kelamin Siswa terhadap Pengetahuan Lingkungan pada Siswa SMP/MTs N dan SMA/MAN Adiwiyata Di Kabupaten Labuhanbatu}

Pada hasil penelitian ini diperoleh bahwa tidak terdapat pengaruh jenis kelamin siswa terhadap pengetahuan lingkungan pada siswa SMP/MTs $\mathrm{N}$ dan SMA/MAN Adiwiyata di Kabupaten Labuhanbatu. Hal ini dikarenakan jenis kelamin siswa belum dapat memiliki dampak pengaruh terhadap pengetahuan siswa dalam memahami pengetahuan terhadap lingkungan. Hal ini dikarenakan pengetahuan tidak memihak kepada gender siswa (status jenis kelamin), melainkan kepada niat siswa untuk mau belajar mengenai lingkungan dan mengambil sikap untuk peduli terhadap lingkungan pula. Oleh sebab itu, pengetahuan seseorang itu berdasarkan bagaimana cara seseorang belajar dan memahami suatu pelajaran dengan baik dan dapat meningkatkan motivasi belajar yang tinggi pada diri sendiri.

Pengaruh Sumber Informasi terhadap Pengetahuan Lingkungan pada Siswa
SMP/MTs N dan SMA/MAN Adiwiyata Di Kabupaten Labuhanbatu

Pada hasil penelitian ini diperoleh bahwa terdapat pengaruh sumber informasi terhadap pengetahuan lingkungan pada siswa SMP/MTs $\mathrm{N}$ dan SMA/MAN Adiwiyata di Kabupaten Labuhanbatu. Hal ini dikarenakan sumber informasi yang diperoleh siswa mempunyai peranan penting bagi para siswa dalam mengetahui lingkungan, masalah lingkungan sehingga lingkungan itu harus perlu dijaga kelestariannya serta menjauhkan dari bencana yang menimpa lingkungan itu juga. Oleh karena itu sumber informasi dari guru, internet, media TV, dan neasehat orang tua memberikan penambahan dan pemahaman siswa mengenai lingkungan. Sehingga disimpulkan terdapat pengaruh secara signifikan sumber informasi terhadap pengetahuan lingkungan pada siswa SMA/MAN dan SMP/MTS N Adiwiyata di Kabupaten Labuhanbatu. Sumber informasi merupakan media yang sangat penting untuk meningkatkan kebutuhan pengetahuan seseorang. Dengan adanya sumber informasi berupa media TV, internet, dan orang tua maupun guru dapat mempengaruhi pengetahuan siswa tentang lingkungan.

\section{KESIMPULAN}

Hasil penelitian ini memberikan kesimpulan bahwa faktor-faktor yang mempengaruhi terhadap pengetahuan siswa tentang lingkungan memiliki peranan penting terhadap sikap kepedulian siswa kepada lingkungan.

\section{DAFTAR PUSTAKA}

Afandi, R. 2013. Integrasi Pendidikan Lingkungan Hidup Melalui Pembelajaran IPS di Sekolah Dasar Sebagai Alternatif Menciptakan Sekolah Hijau. Pedagogia Universitas Muhammadiyah Sidoarjo, 2(1): 98-108.

Al-Anwari, A. 2014. Strategi Pembentukan Karakter Peduli Lingkungan di Sekolah Adiwiyata Mandiri.Ta'dib IAIN Sulthan Thahah Saifuddin Jambi. 19(2): 112-130.

Aprilia, N. 2015. Evaluasi Pengelolaan Sarana Pendukung yang Ramah Lingkungan pada 
Program Adiwiyata di SMP Muhammadiyah di Kota Yogyakarta. Yogyakarta: Universitas Ahmad Dahlan.

Arikunto, S. 2007. Prosedur Penelitian.Jakarta: Rineka Cipta.

Astalin, P.K. 2011. A Study of Environmental Awareness Among Higher Secondary Students and Some Educational Factors Affecting It. International Journal of Multidisciplinary Research, 1(7): 90-101.

Azwar, S. 2010. Metode Penelitian. Yogyakarta: Pustaka Pelajar.

Dewi, R. 2009. Studi Kasus Pengetahuan dan Kepedulian terhadap Lingkungan Hidup. Majalah Kedokteran Damianus, 8(2): 115124.

Divya and Katie, W. 2004. Factors Affecting Environmental Concern in Bloomington Normal Residents. The Park Place Economist, 12(1) : 101-117.

Hamzah, S. 2013. PendidikanLingkungan Sekelumit WawasanPengantar. Bandung: Refika Aditama.

Hidayati, N., Taruna, T., dan Purwaweni, H. 2013. Perilaku Warga Sekolahdalam Program Adiwiyata di SMKNegri 2 Semarang.Semarang:Prosiding Seminar Nasional Pengelolaan Sumberdaya Alam dan Lingkungan Universitas Diponegoro (UNDIP).

Jumadil, K., dan Hamzah, A. 2015. Penerapan Program Adiwiyata pada Aspek Kognitif, Afektif dan Psikomotor Tentang Pengelolaan Lingkungan Hidup Sekolah Dasar di Kota Kendari.Jurnal Sains dan Teknologi, 15(2):115-125.

Kementerian Negara Lingkungan Hidup. 2012. Panduan Adiwiyata. Jakarta: Konservasi Nasional Lingkungan Hidup.

Keraf, A.,S. 2002. Etika Lingkungan. Jakarta: Buku Kompas.

Kumurur, V. 2008.Pengetahuan, Sikap, dan Kepedulian Mahasiswa Pascasarjana Ilmu Lingkungan terhadap Lingkungan Hidup Kota Jakarta.Ekoton Universitas Sam Ratulangi Manado, 8(1): 1- 24.

Landriany, E. 2014. Impementasi Kebijakan Adiwiyata dalam Upaya Mewujudkan Pendidikan Lingkungan Hidup di SMA Kota Malang. Jurnal Kebijakan dan Pengembangan Pendidikan. 2(1): 110-143.

Monalisa. 2013. Program Adiwiyata dalamPengelolaan Lingkungan Sekolah di SMPN 24 Padang. Artikel diakses pada tanggal 15 April 2016.
Mulyana, R. 2009. Penanaman EtikaLingkungan Melalui Sekolah Perduli dan Berbudaya Lingkungan. Jurnal Tabularasa Program Pascasarjana Universitas Negeri Medan. 6(2):175-180.

Neolaka, A. 2007. KesadaranLingkungan. Jakarta: Rineka Cipta.

Notohadiprawiro. 2006. PendidikanLingkungan. Yogyakarta: Universitas Gajah Mada.

Piaget, J. 1977. Equilibration of Cognitive Structures. New York: Viking.

Pratomo, S. 2009. ModelPembelajaran Tematik dalam Pendidikan Lingkungan Hidup (PLH) di Sekolah Dasar. Jurnal Pendidikan Dasar Respository Universitas Pendidikan Indonesia Bandung, 11(2): 8-15.

Purwati, A. 2011. Pengaruh Status Sosial Ekonomi Orang Tua, Persepsi atas Lingkungan, dan Prestasi Belajar. Jurnal Ekonomi Bisnis Malang, 16(1): 18-116.

Saragih, A. 2012.Pengaruh Program Adiwiyata terhadap Kognitif Afektif dan Psikomotorik Lingkungan Hidup Siswa Sekolah Dasar di Kota Medan. Medan: Universitas Sumatera Utara.

Shobeiri, S.M., Omidar, B., and Prahallada, N. 2007. A Comperative Study of Environmental Awarness among Secondary School Students in Iran and India. International Journal Environment Research, 1(1): 28-34.

Sidauruk, T., Suriani M., dan Restu. 2013. Profil Perilaku Lingkungan HidupSiswa SMA Negeri di Kota Medan.JUPIIS, 5(1):10-45.

Slameto. 2010. Belajar dan Faktor-faktor yang Mempengaruhinya. Jakarta: Rineka Cipta.

Sudjana. 2002. Metoda Statistik. Bandung: Tarsito.

Sugyono. 2011. Metode Penelitian Kuantitatif dan Research and Development $(R \& D)$. Bandung: Alfabeta.

Sumarmi. 2008. Sekolah Hijau Sebagai Alternatif Pendidikan Lingkungan Hidup dengan Menggunakan Pendekatan Kontekstual. Jurnal Ilmu Pendidikan: Lembanga Pendidikan dan Tenaga Pendidikan (LPTK) dan Ikatan Sarjana Pendidikan Indonesia (ISPI) Malang, 15(1): 19-25.

Syamsul, K. 2013. Pendidikan Karakter. Yogyakarta: Ar-Ruzz Media. 